\title{
Por uma Antropologia na Caatinga: um breve ensaio sobre o bacharelado em Antropologia na Univasf e a interiorização do ensino superior no Brasil
}

For an anthropology in Caatinga: brief essay on the Anthropology bachelor's program at Univasf and the interiorization of higher education in Brazil

\section{Natacha Simei Leal}

\section{(2) OpenEdition}

\section{Journals}

\section{Edição electrónica}

URL: http://journals.openedition.org/aa/7657

DOI: $10.4000 /$ aa. 7657

ISSN: 2357-738X

\section{Editora}

Programa de Pós-Graduação em Antropologia Social (UnB)

\section{Edição impressa}

Paginação: 39-57

ISSN: 0102-4302

\section{Refêrencia eletrónica}

Natacha Simei Leal, «Por uma Antropologia na Caatinga: um breve ensaio sobre o bacharelado em Antropologia na Univasf e a interiorização do ensino superior no Brasil», Anuário Antropológico [Online], v.46 n.1 | 2021, posto online no dia 03 janeiro 2021, consultado o 27 abril 2021. URL: http:// journals.openedition.org/aa/7657 ; DOl: https://doi.org/10.4000/aa.7657

\section{(c) $(1)$}

Anuário Antropológico is licensed under a Creative Commons Atribuição-Uso Não-Comercial-Proibição de realização de Obras Derivadas 4.0 International. 


\title{
Por uma Antropologia na Caatinga: um breve ensaio sobre o bacharelado em Antropologia na Univasf e a interiorização do ensino superior no Brasil
}

\author{
For an anthropology in Caatinga: \\ brief essay on the Anthropology bachelor's program at Univasf and the \\ interiorization of higher education in Brazil
}

\author{
DOI: https://doi.org/10.4000/aa.7657
}

\begin{abstract}
Natacha Simei Leal • Universidade Federal do Vale do São Francisco - Brasil
Professora Adjunta do Colegiado de Antropologia da UNIVASF, campus Serra da Capivara. Doutora e mestra em Antropologia Social pela Universidade de São Paulo (USP), é pesquisadora associada ao Hybris (Grupo de Estudo e Pesquisa sobre Relações de Poder, Conflitos, Socialidades - USP/UFSCar), ao NuAP (Núcleo de Antropologia Política - UFRJ, Museu Nacional) e ao LaMPda (Laboratório de Metodologia, Pesquisa e Documentação em Antropologia, CANT - UNIVASF).
\end{abstract}

O presente ensaio tem o intuito de registrar um momento muito importante, mas igualmente difícil, para as ciências humanas e as universidades públicas brasileiras, a partir de minha experiência como docente do recente bacharelado em Antropologia da Univasf (Universidade Federal do Vale do São Francisco), campus Serra da Capivara. Com base em reflexões que tiveram início com uma mesa sobre Novas Universidades promovida na $31^{\circ}$ reunião da Associação Brasileira de Antropologia (ABA), pela análise da pujança dos conhecimentos arqueológicos em São Raimundo Nonato, Piauí - cidade sede do campus Serra da Capivara -, de uma breve história do desenvolvimento econômico do Vale do São Francisco que culminou na fundação da Univasf no ano de 2004 e, por fim, de uma reflexão sobre o que vem sendo produzido por alunos e professores de Antropologia da mesma universidade, o texto pretende apresentar os desafios, impasses e perspectivas da expansão e interiorização do ensino superior em um pequeno município do semiárido brasileiro, em especial, num momento de incessantes cortes de recursos.
The purpose of this essay is to record a very important, but equally difficult, moment for the humanities and Brazilian public universities based on my experience as a professor at the recent bachelor's degree in Anthropology at Univasf (Federal University of Vale do São Francisco), Serra da Capivara campus. According to some reflections that began with a conference on New Universities, promoted at the 31st meeting of the Brazilian Association of Anthropology (ABA), by analyzing the strength of archaeological knowledge in São Raimundo Nonato, Piauí - the town of the Serra da Capivara campus-, a brief history of the economic development of the São Francisco Valley that culminated in the foundation of Univasf in 2004, and, finally, a reflection on what has been produced by students and professors of Anthropology at the same university, the text intends to present the challenges, impasses and perspectives of the expansion, and internalization of higher education in a small municipality in the Brazilian semiarid region, especially at a time of incessant cuts in resources.

Anthropology. Caatinga. Higher Education Expansion. Piauí. 
Gostaria de dar início a este ensaio refletindo sobre a satisfação de escrever sobre o curso de graduação em Antropologia do campus Serra da Capivara da Universidade Federal do Vale do São Francisco ${ }^{1}$, onde trabalho como docente. A ocasião é oportuna porque no ano de 2020 formamos a nossa primeira turma, e registrar este breve percurso é essencial. Mas penso que as universidades públicas - fundamentadas na tríade pesquisa, ensino e extensão - e especialmente aquelas localizadas no interior do Brasil têm uma outra função: elas alteram dinâmicas (econômicas, culturais e políticas) de pequenos municípios brasileiros.

Com a chegada de docentes e técnicos para trabalhar nestas pequenas cidades, amplia-se a procura por serviços (aluguéis, restaurantes, atividades desportivas, de lazer e de saúde). Alunos e alunas, com suas bolsas permanência de pesquisa e extensão se tornam consumidores. Jovens vindos de outras regiões para estudar nesses campi trazem em sua bagagem outras formas de sociabilidade, por vezes, inclusive, conflitivas com a desses pequenos municípios.

Assim, estudantes dessas universidades públicas passam a gozar de um lugar, senão de prestígio, ao menos de destaque. Debates sobre gênero, questões raciais, políticas culturais e saúde mental, por exemplo, tornam-se latentes, gerando efeitos, inclusive, nas maneiras como as próprias prefeituras passam a lidar com parte de seus munícipes agora vindos de outros lugares, sem redes familiares e com outras percepções e experiências sobre o papel do poder público. E aqueles nascidos e criados nestas pequenas cidades, decididamente eleitores, quando entram na universidade, paulatinamente, se tornam cada vez mais críticos.

Se este breve diagnóstico não é necessariamente comum a todos os pequenos municípios que receberam campi universitários a partir de meados dos anos 2000 com o Programa de Expansão da Educação Superior Pública (EXPANDIR, 2003-2006) e o Programa de Apoio aos Planos de Expansão e Reestruturação de Universidades Federais (REUNI, 2007-2012), ele é certamente decisivo para São Raimundo Nonato - PI, sede do campus Serra da Capivara da Univasf. Desta feita, entendo que o registro da interlocução e os efeitos que o curso de Antropologia tem provocado nesta cidade e em toda a região do Sudeste do Piauí justifica, por si só, o porquê de desenvolver este ensaio.

São Raimundo Nonato é uma cidade polo ${ }^{2}$ do Sudeste do Piauí. Distante da capital Teresina por 550 quilômetros, apesar de pequena, com cerca de $35 \mathrm{mil}$ habitantes, atende a muitos moradores dos municípios do entorno. Segundo o IBGE, as métricas indicadoras de desenvolvimento - como o IDHM (Índice de Desenvolvimento Humano) e PIB (Produto Interno Bruto) - melhoraram substancialmente nos últimos quinze anos, não coincidentemente no mesmo período em que a Univasf se instala no município. Mesmo assim, 45,8\% da população com rendimentos formais recebe menos de meio salário mínimo por mês ${ }^{3}$. Apesar de o comércio ser pujante, capaz de empregar bastante gente, parte da população produz e comercializa produtos de suas roças localizadas na zona rural de São Raimundo ou nos pequeníssimos ${ }^{4}$ municípios da região, popularmente chamados de interior.

Interior, inclusive, foi o termo que muitos alunos e alunas usaram no primeiro
1 Gostaria de agradecer pelas trocas de informações, artigos e conversas sobre a Univasf, fundamentais para a construção deste ensaio, aos colegas Leandro Mageste e Vivian Karla Sena de Sena, aos meus queridos alunos Edmar dos Santos Mota e Tainara Santana Castro e à Lauriene Seraguza pela generosa leitura de uma das versões deste artigo. Categorias nativas aparecerão ao longo do texto em itálico.

2 Tais dados sobre a cidade de São Raimundo Nonato podem ser acessados pelo seguinte endereço: https:// cidades.ibge.gov.br/brasil/pi/ sao-raimundo-nonato/panorama. Acesso em: 9 nov. 2019.

3 Uma pesquisa feita por professores da Univasf na ocasião das manifestações de 18 de maio de 2019 contra os cortes da educação mostrou que os salários de técnicos e professores, além das bolsas permanência, de pesquisa e de extensão das duas instituições federais de ensino instaladas em São Raimundo Nonato (IFPI e Univasf), correspondem a um quarto do orçamento do município. Ou seja, a presença destas universidades é decisiva para o setor de comércio e serviços da cidade, bem como para a manutenção de empregos indiretos.

4 O mestrado de Emília Godoi,O trabalho da memória: um estudo antropológico de ocupação camponesa no sertão do Piauí (1993), realizado a partir de uma pesquisa de campo entre os anos de 1986 e 1988 em uma comunidade camponesa localizada em São Raimundo, apresenta que a cidade, naquela época, tinha 57.721 habitantes. Hoje a cidade tem cerca de 35.000 habitantes porque um conjunto de localidades de seu entorno foi emancipado, tornando-se municípios. Apesar destas emancipações, São Raimundo segue atendendo - com serviços, comércio e equipamentos estatais - 18 municípios do Sudeste do Piauí, a saber: Anísio de Abreu (7166 habitantes), Bonfim do Piauí (4880 
dia de aula do curso de Antropologia da Univasf. Naquele momento de recém-chegada ao Piauí, ainda muito impactada com as diferenças infraestruturais da região em relação à cidade de São Paulo - onde morei durante dez anos para cursar meu mestrado e doutorado - e ainda me acostumando com a vida em uma cidade que, naquele momento, considerava muito pequena, me embasbaquei e concomitantemente me situei quando boa parte de nossos estudantes disseram ao se apresentarem: "Sou do interior de São Raimundo!".

Ainda não tinha a dimensão de que São Raimundo Nonato sediava muitos equipamentos estatais (Justiça Federal, IBGE, IPHAN, ICMBio, Receita Federal, Justiça do Trabalho, Fórum Estadual, Correios, Detran), o Hospital Regional e as agências bancárias de toda a região. Sabia da presença das três instituições públicas de ensino superior na cidade - a Uespi (Universidade Estadual do Piauí), o IFPI (Instituto Federal do Piauí) e a Univasf (Universidade Federal do Vale do São Francisco) - e, claro, do equipamento cultural mais famoso do município que inclusive nomeia o campus: o Parque Nacional da Serra da Capivara, um patrimônio mundial da humanidade.

O trabalho da Missão Arqueológica Franco-Brasileira do Piauí, liderado pela Professora Niéde Guidon, acontece nas proximidades de São Raimundo Nonato desde o início da década de 1970. Conta-nos Guidon (2007) que a presença de um conjunto expressivo de pinturas rupestres na região - a maior concentração das Américas -,estimulou que em 1978 a missão requisitasse ao governo brasileiro a criação de um projeto de lei de uma unidade de conservação localizada em territórios do município de São Raimundo Nonato. O intuito da criação do parque foi o de preservar sítios arqueológicos que, conforme a tese da própria arqueóloga, evidenciam a presença humana na região em até 100.000 A.P, sugerindo a revisão da datação de teorias consolidadas sobre a chegada e presença do Homo Sapiens na América.

Tais pesquisas foram decisivas tanto para a instalação em São Raimundo Nonato da Fundação do Homem Americano (FUMDHAM) - uma entidade civil, sem fins lucrativos e de interesse público que realiza pesquisas interdisciplinares liderada por Guidon - em 1986 e do Parque Nacional da Serra da Capivara, quanto para a criação da primeira graduação em Arqueologia de uma universidade pública brasileira nesta mesma cidade. O curso de Bacharelado em Arqueologia e Preservação Patrimonial da Univasf nasce junto com a fundação da própria universidade, no ano de 2004.

Já o curso de Antropologia é bem mais recente, de 2016. Como me contam alunos e professores da Univasf que estavam na universidade desde o seu início, a fundação do curso de Antropologia foi fruto de uma consulta popular. Havia a possibilidade de ampliação de graduações da Univasf no campus Serra da Capivara. Dessa feita, realizou-se no município de São Raimundo Nonato uma consulta pública para que a população escolhesse que cursos gostaria de ter na cidade e, curiosamente, Antropologia foi um dos escolhidos. Decerto a proximidade com a Arqueologia foi uma das razões por esta escolha, mas não deixa de ser inusitado que o curso de Antropologia tenha sido escolhido em detrimento de bacharelados habitantes), Campo Alegre do Fidalgo (4459), Capitão Gervásio de Oliveira (3427 habitantes), Caracol (8047 municípios), Coronel José Dias ( 4416 habitantes),Dirceu Arcoverde (6067 habitantes), Dom Inocêncio ( 8909 habitantes), Fartura do Piauí (4659 habitantes), Guaribas (4812 habitantes), João Costa (2932 habitantes), Jurema (4043 habitantes), Lagoa do Barro do Piauí (4440 habitantes) São Braz do Piauí (4193 habitantes), São João do Piauí (17. 666 habitantes), São Lourenço do Piauí (17.666 habitantes) e Várzea Branca (5206 habitantes). 
como Arquitetura, Geografia, História e Geologia, que poderiam ser, igualmente, instalados no campus Serra da Capivara.

Quando eu estava afinando as ideias que deram origem ao presente ensaio, me dei conta de um fato. Ao longo da minha carreira, eu sempre fui chamada para escrever artigos e compor mesas ou grupos de trabalho que tratavam de Antropologia Rural, Antropologia da Ciência, Organização Social e Parentesco, Antropologia Política ou Antropologia das Relações Humano-Animais. Acontece que nos últimos tempos, e não apenas porque eu me tornei coordenadora do CANT (Colegiado de Antropologia da Univasf), tenho sido convocada para refletir sobre as condições de possibilidade de exercício da Antropologia no Brasil.

Penso que isso é efeito de um contexto bastante controverso. Seja porque as universidades públicas brasileiras vêm sofrendo cortes consideráveis desde pelo menos 2016 com a PEC dos gastos, seja porque a Ciência (e em especial as ciências humanas) estão sob constantes suspeitas. Assim, antes de eu falar sobre o projeto do Bacharelado de Antropologia da Univasf, gostaria de retomar algumas ideias que tenho produzido em parceria com alguns colegas.

\section{As novas universidades. 0 fim e o começo de mundos}

Na $31^{a}$ Reunião da Associação Brasileira de Antropologia (ABA), que aconteceu em dezembro de 2018 em Brasília, junto com os colegas Rafael Noleto, Diógines

Cariaga e Rafael Antunes de Almeida que atuam ou atuaram em novos campus e universidades - UFT (Universidade Federal do Tocantins, campus Tocantinópolis-TO), UEMS(Universidade Estadual de Mato Grosso do Sul, campus Amambai-MS) e Unilab (Universidade de Integração Internacional da Lusofonia Afro-Brasileira, campus Redenção-CE) -, propusemos uma mesa para discutir uma espécie de estado da arte da expansão e interiorização do ensino superior no Brasil e os efeitos que isso vem produzindo para o ensino, pesquisa e extensão em Antropologia e Ciências Sociais em pequenos municípios do país.

Apresentamos nossas próprias experiências como docentes a partir do quadro geral das políticas públicas - como o Programa de Expansão da Educação Superior Pública (EXPANDIR, 2003-2006) e o Programa de Apoio aos Planos de Expansão - que, através da criação de universidades multicampi e de novos cursos de graduação, atenderam às chamadas "vocações locais" de diversas regiões do interior do país, como o Vale do São Francisco. Nessa ocasião, debateu-se o exercício da docência em Antropologia fora dos grandes centros de formação em Ciências Sociais.

O debate foi muito rico e, diga-se de passagem, caloroso. Seja porque se evidenciaram as especificidades de pesquisa, ensino e extensão de cada um desses novos campi e universidades que trazem contribuições até então impensáveis para as ciências e a vida universitária brasileira, mas especialmente porque o público que assistia a essa mesa era composto, majoritariamente, por estudantes dessas novas universidades, muitos nascidos em cidades do interior do Brasil. Esses alunos e alunas ali presentes nos colocaram uma chuva de questões e entre elas uma 
bastante capciosa: "Por que nossos professores passam nos concursos e logo vão embora?".

Eu explico. Em boa medida, porque as condições de possibilidade de acessar recursos para a pesquisa não são as mesmas que as dos grandes centros onde boa parte desses professores cursou seus mestrados e doutorados. Tal fato, acrescido da distância das redes familiares e das cidades de origem do corpo técnico e docente desses campi, faz com que a rotatividade de servidores seja constante (ou a menos era quando havia mais ofertas de concursos ou empregos). Colegas da Arqueologia da Univasf narram, por exemplo, que ao menos duas dezenas de docentes passaram pelo Colegiado desde a sua fundação.

$\mathrm{Na}$ Univasf há poucas bolsas de iniciação científica e os critérios de acesso a estes parcos recursos são, em boa medida, fundamentados pelas métricas de produtividade das ciências agrotécnicas, exatas e da saúde, que são incompatíveis com as das ciências humanas e sociais. Além disso, a Fundação de Amparo à Pesquisa do Estado do Piauí (Fapepi), com quem deveríamos contar para realizar nossas pesquisas, possui pouquíssimos editais para a realização de eventos e estudos. A referida fundação ainda não dispõe de bolsas de iniciação científica, mestrado e doutorado capazes de subsidiar as pesquisas de nossos alunos e mesmo pesquisas de professores.

E isso é difícil? Tenho que admitir que é sim! Mas é impossível produzir conhecimentos nessas condições? Não! E sobre isso volto a falar quando apresentar o que o Colegiado de Antropologia tem feito aqui na Univasf e no Sudeste do Piauí.

Outro desses momentos recentes de discutir o exercício da Antropologia foi a abertura da Semana de Ciências Sociais da Univasf, campus de Juazeiro, de 2018. Eu fui convidada para falar numa mesa que tinha como tema "Educação e o ensino de Ciências Sociais". Fazia bem pouco tempo da ocorrência do incêndio no Museu Nacional e eu intuí que talvez fosse o caso de promover uma reflexão sobre isso.

E por quê? A Antropologia costuma estudar populações cujo mundo, na forma de sua cosmologia e cultura material, de certo modo, acabou. E pesquisas recentes vêm mostrando, através de uma miríade de etnografias, como essas populações, quando resistem, reagem com muita criatividade com o fim de seus mundos.Com alegria ou com tristeza, com falas fortes ou rezas, em rituais, participando de assembleias ou da política nacional, nas bordas ou no centro, com e contra o Estado, empreendem, cotidianamente, formas de luta.

A eminência e os efeitos do fim do mundo, inclusive, têm sido tema de publicações recorrentes, como aquela de Déborah Danowski e Eduardo Viveiros de Castro (2014) que, entre outras coisas, analisa um certo "mundo por vir" na chave das transformações do regime termodinâmico do planeta e suas relações com causas antrópicas - como a crise a ambiental e populacional - que a comunidade científica mundial, a partir do artigo seminal de Crutzen e Stoermer (2000), entende como um novo período geológico nomeado como Antropoceno.

Não pretendo aqui desconsiderar os decisivos debates levantados pela comunidade científica sobre o Antropoceno, e eles não estão completamente distantes do fim de um mundo, neste caso o mundo incendiado no Museu Nacional. Como 
Danowski e Viveiros de Castro (2014) afirmam, a eminente ruína de nossa espécie em virtude de um desequilíbrio energético do sistema Terra pelo acúmulo de gases é um efeito de uma contracorrente humanista produzida por ações e projetos de parte desta mesma espécie, que hoje corre o risco de ser extinta. Mas é fundamental lembrar que outros coletivos - que não a dos cientistas - já vinham enunciando ou lidando com a eminência do fim de seus mundos há bastante tempo.

A etnografia de Márcia Nóbrega (2019), por exemplo, descreve como comunidades ribeirinhas da Ilha de Massangano (PE) que habitam as margens do Rio São Francisco viram a transformação de suas terras, correntezas, povoações, modos de existir e, assim, de seus mundos em razão do embarreiramento de águas desde a construção da barragem de Sobradinho (considerada, não obstante, como um empreendimento decisivo para as políticas de desenvolvimento de todo o Vale do São Francisco, conforme mostrarei em páginas a seguir).

A correnteza do rio que havia no "tempo de primeiro", narra Nóbrega, carregava gente, mercadorias, mas também espíritos afeitos às águas - o caboclos -, e, deste modo, os ribeirinhos faziam seu mundo (na terra e no rio) sempre em movimento. Hoje, o fluxo do rio é controlado por dispositivos político-tecnológicos empregados por técnicos da CHESF (Companhia Hidrelétrica do São Francisco) que decidem como despejarão águas no São Francisco, impedindo os beiradeiros, vazanteiros e barranqueiros de Massangano de prever os regimes de cheia ou vazante decisivos para sua agricultura e mesmo para seu modo de existir, habitar e circular pelo mundo.

Talvez a experiência dos ribeirinhos da Ilha de Massangano, e de tantos outros coletivos que lidam com a eminência do fim de seus modos de existir e mundos, nos ensine sobre os cortes sucessivos às ciências humanas e à Cultura no Brasil que culminaram na destruição do Museu Nacional. O fato é que o incêndio no Museu destruiu o mundo e o modo de existir de muita gente (no caso, o mundo de Antropólogos, Arqueólogos, Biólogos, Paleontólogos...). Junto com incêndio de livros, notas de campo, ossadas, fósseis, múmias, cerâmicas e registros linguísticos foi queimada parte de nossa cosmologia e Cultura. Foi queimada uma espécie de mundo-modelo para os antropólogos, que dava sentido e era parte de nossa existência.

Eu não estudei no Museu Nacional, mas tenho plena consciência de que a antropologia produzida ali era (e é) interessante porque permitia a realização de pesquisas. Os professores que ali trabalham dedicam-se única e exclusivamente à pós-graduação. Por disporem de recursos materiais (como, por exemplo, a maior biblioteca de antropologia da América Latina), tinham mais possibilidades que os demais docentes das universidades do Brasil de desenvolver estudos, estar atualizados em debates teóricos, fazer trabalho de campo, criar e consolidar grupos de pesquisa.

Na introdução de uma recentíssima coletânea, "Insurgências, Ecologias Dissidentes e Antropologia Modal” (2020), Jorge Mattar Villela e Suzane Alencar Vieira analisam o incêndio do Museu Nacional. Refletem, a partir desta tragédia, como incêndios operam como armas de esbulhamento. Lembram que incêndios foram 
tecnologias centrais para os processos de limpeza ética na história dos estados-nacionais europeus, que lança-chamas foram armas diletas de nazistas e que, no sul dos Estados Unidos, milhares de afroamericanos foram queimados em cruzes. No Brasil, como bem sabemos e lembram os autores, florestas e comunidades inteiras são sucessivamente incendiadas. A sugestão de Vilela e Vieira (2020) é, assim, explícita: a ruína do acervo, do prédio e das vidas que se produziam no Museu Nacional através das pesquisas ali realizadas, foi mesmo um assassinato, um genocídio.

É claro, como também lembram Vilela e Vieira (2020), que esse incêndio não foi um simples acidente. A gente ouviu falar na imprensa que não havia água nos hidrantes, que o Museu recebia muito menos recursos do que deveria e que o prédio, centenário, não recebia as manutenções adequadas. E estou duplamente de acordo com as falas do antropólogo Eduardo Viveiros de Castro em uma entrevista ${ }^{5}$ que deu no dia 4 de setembro de 2018 a um jornal português sobre o incêndio no Museu. Como ele, acho que nada deveria ser reconstruído naquele lugar. As ruínas do Museu Nacional, como sugere Viveiros de Castro, poderiam ficar ali como um monumento - a ser estudado pelos colegas arqueólogos, quem sabe - à memória dos mortos, das coisas mortas, dos povos mortos, dos arquivos mortos, destruídos naquele incêndio. E também concordo com o antropólogo que essa tragédia é um efeito de um projeto nacional de devastação e de criação de desertos.

A questão é como lidar com esse projeto nacional de devastação e criação de desertos que tem se materializado nos cortes sucessivos de recursos e apoio para as Ciências Humanas e às universidades públicas expressivamente nos últimos cinco anos. E, mais especificamente, como alunos e professores da Antropologia da Univasf, um curso novo fundado em 2016 em meio à "PEC do fim do mundo", e que realiza suas atividades em uma universidade na Caatinga - considerada por muita gente como seca, quente, infértil, naturalmente desértica - podem reagir.

\section{A Univasf, o Semiárido e a Caatinga}

No campus da Univasf da Serra da Capivara tudo está sendo construído. Esse é o nosso trunfo e nós, alunos e professores, reagimos todos os dias. Juntos, docentes - bastante jovens, diga-se de passagem - estudantes, técnicas e técnicos dos Bacharelados em Arqueologia, Antropologia e das Licenciaturas em Ciências da Natureza e Química, presentes no campus, cotidianamente, tentamos construir uma universidade humanística e inclusiva, capaz de, por um lado, suprir as inegáveis demandas de inovação e desenvolvimento de uma das regiões mais pobres do país, mas, sobretudo, oferecer aos nossos alunos e alunas uma formação cidadã.

A Univasf foi a primeira universidade federal a distribuir seus campi em mais de um estado brasileiro: desde sua fundação é multicampi se fazendo presente em Pernambuco, na Bahia e no Piauí. Organizada em sete campi distribuídos em seis municípios do semiárido nordestino (Petrolina-PE, Juazeiro-BA, São Raimundo Nonato-PI, Senhor do Bonfim-BA, Salgueiro-PE e Paulo Afonso-BA), nasceu há 16
5 Ver entrevista com Eduardo Viveiros de Castro em Coelho (2018). Disponível em: http:// www.publico. pt/2018/09/04/ culturaipsilon/entrevista/eduardo-viveiros-de-castro-gostaria-que-o-museu-nacional-permanecesse-como-ruina-memoria-das-coisas-mortas-1843021. Acesso em: 10 nov. 2019. 
anos atrás, com a missão de "interiorizar" a formação superior, no sentido lato do termo.

A universidade é jovem em mais de um sentido. Jovem porque tem 16 anos, porque sua estrutura burocrática e administrativa é bastante distinta das universidades mais antigas e consolidadas (e sobre isso falarei mais detidamente a seguir), mas fundamentalmente porque seu corpo docente e técnico tem pouca idade. Os últimos reitores eleitos, por exemplo, assumiram seus cargos com menos de 40 anos: o reitor tinha 35 anos e o vice-reitor, 34 .

É uma universidade que se propõe a desenvolver uma região, o Vale do São Francisco, que há muitos anos tem sido foco de políticas públicas e, por essa razão, objeto de estudos e trabalhos clássicos e potentes das ciências sociais, como os de Donald Pierson, O Homem no Vale do São Francisco (1972), e Lygia Sigaud, Efeitos Sociais de Grandes Projetos Hidrelétricos: As Barragens de Sobradinho e Machadinho (1986). O longo estudo de comunidade desenvolvido por Pierson a partir de uma pesquisa coletiva realizada na década de 1950, teve apoio da Escola de Sociologia e Política, Superintendência do Vale do São Francisco e Comissão do Vale do São Francisco. Já Sigaud, apresenta uma brilhante etnografia que analisa os impactos da instalação daquela usina hidrelétrica no Rio São Francisco nas populações ribeirinhas do Vale.

Obras e projetos imponentes, como a já mencionada construção da Barragem de Sobradinho e, mais recentemente, a transposição do Rio São Francisco e a instalação de fazendas de energia eólica e solar, vêm sendo empreendidos a fim de solucionar problemas com a seca e desenvolver economicamente toda a região cortada pelo chamado "Rio da Integração Nacional". A irrigação, por exemplo, que contemporaneamente, parece ser a pedra de toque fundamental para consolidar o polo do agronegócio fruticultor e de vinhos em Juazeiro-BA e Petrolina-PE, acontece no Vale desde a década de 1940.

Conforme demonstra o sociólogo José Fernando Souto Jr. (2019), o submédio do Vale do São Francisco se destaca, nas últimas décadas, na produção mundial de frutas. O polo Juazeiro-Petrolina, contemporaneamente, é o terceiro maior exportador de frutas do planeta. Os números suntuosos desta exportação (cerca de 43,8 milhões de toneladas por ano) são efeito, no entanto, de um longo processo de investimentos, envolvendo inúmeras instituições públicas (Sudene, Codevasf, Banco do Nordeste, Embrapa)e a iniciativa privada, capazes de transformar as terras secas do semiárido brasileiro em terras irrigáveis com as águas do Rio São Francisco. Os projetos de irrigação no Vale, lembra o autor, têm sua gênese ainda na década de 1940, com a criação da Companhia Hidrelétrica do Vale do São Francisco, mas ganham fôlego, sobretudo, a partir da década de 1960 com a criação da Sudene e a fundação, em 1963, de duas estações experimentais de irrigação instaladas na região através do Grupo de Irrigação do Vale do São Francisco. Ou seja, como analisa Souto Jr., a pujança contemporânea do agronegócio fruticultor de Petrolina e Juazeiro é efeito de um projeto de desenvolvimento econômico do Vale do São Francisco de, pelo menos, 60 anos. E em boa medida, esse lócus e esse projeto de desenvolvimento do Vale orientaram a fundação da Univasf em meados 
dos anos 2000 e ainda orienta sua política científica.

Não sem razão, a universidade conta com muitos cursos de graduação e pós-graduação em engenharia e ciências agrárias: a Univasf é uma universidade da inovação, anseia se constituir como uma importante produtora de patentes para desenvolver tecnologias agrárias na Caatinga. $E$ se isso, por um lado, se faz positivo, por outro lado, os únicos quatro cursos decididamente de humanas da universidade (Antropologia, Arqueologia, Artes e Ciências Sociais), como disse em momento anterior, têm de enfrentar as métricas e os critérios de produtividade das ciências duras.

Além disso, a Univasf tem uma estrutura burocrática e administrativa um tanto peculiar. Não existem faculdades ou centros na Univasf. Não há, por exemplo, diretores de centro ou chefes de departamento no campus da Serra da Capivara ou em qualquer outro campus da universidade. A universidade se estrutura fundamentalmente em colegiados, os quais estabelecem relações sem intermediários (centros, departamentos, faculdades) com a reitoria. O conselho superior da universidade - que aqui chamamos de Conuni - conta com conselheiros representantes de todos os colegiados de graduação e pós-graduação, além de técnicos, corpo discente e membros da comunidade externa.

Se esta estrutura um tanto horizontalizada que objetiva criar menos hierarquias em uma universidade que está presente em três estados da federação permite uma conversa mais direta entre reitoria e colegiados sobre as demandas de cada curso no Conselho Universitário e nas inúmeras câmaras como as de Ensino, Pesquisa, Extensão e Assistência Estudantil (que, igualmente, requerem entre seus membros representantes de cada um dos colegiados de curso da instituição), o trabalho burocrático dos professores é intenso. Na Univasf, todo o corpo docenteseja no conselho, nas câmaras ou em demais comissões- necessariamente, tem de trabalhar com ensino, pesquisa, extensão e administração universitária.

Como todos os coordenadores de curso são necessariamente conselheiros da máxima instância deliberativa e consultiva da Universidade (o Conuni), aprendemos desde que entramos na instituição como funciona a distribuição de recursos pelo MEC (Ministério da Educação), o que é uma LOA (Lei Orçamentária Anual),o quanto as fatias das emendas parlamentares produzem orçamentos. Enquanto docente, há menos de quatro anos já avaliei pelo menos dois processos administrativos (os famosos PAD’s) que aplicam sanções ou mesmo a demissão de colegas e fui relatora ou tive de participar da construção de um apanhado de resoluções que dão conta de legislar questões na ampla área em que a Univasf atua.

Há ainda uma outra questão. São Raimundo não está localizada no Vale do São Francisco, está no Piauí. Ainda que o vínculo com o Vale seja indubitável, na medida em que, pelo discurso oficial da História, a cidade foi fundada pelos vaqueiros e tropeiros que ao avançarem do Vale São Francisco para o rio Piauí instalaram onde se hoje se localiza São Raimundo, fazendas e moradas (Oliveira, 2007), o rio (São Francisco) fica a 100 quilômetros da cidade, na vizinha Remanso-BA. E a própria ideia de integrar várias cidades localizadas no Vale do São Francisco em uma única universidade não estava propriamente dada na proposta inicial de 
fundação da Univasf.

O Projeto de Lei 5307/2001,apresentado à Câmara Legislativa por políticos pernambucanos ainda no governo Fernando Henrique, tinha como proposta a criação da Universidade Federal de Petrolina (Rodrigues, 2019). O projeto, naquele momento anterior às políticas de expansão universitária do governo do Lula que criaram várias universidades multicampi, era um tanto inovador. Como mostram documentos da Câmara Legislativa ${ }^{6}$ que registram a série de debates, relatórios, comissões e pareceres sobre o tema, a bancada pernambucana que defendia a criação da instituição em Petrolina argumentava que esta seria a primeira universidade federal do estado cuja sede não estaria localizada na capital, Recife.

Igualmente interessante foi a pressão de políticos da vizinha baiana de Petrolina - Juazeiro - pela ampliação daquela nascente universidade. Esta série de documentos mostra que membros da bancada da Bahia argumentavam que seu estado, naquele início dos anos 2000, só tinha uma universidade federal, a UFBA, e que não havia sentido privilegiar apenas uma destas cidades porque Petrolina e Juazeiro eram vinculadas na economia, história, no território e nas tradições pelo Rio São Francisco. Desta feita, entrou-se em consenso que esta nova universidade se faria presente em ambos os estados (Pernambuco e Bahia) e seria nomeada como Universidade Federal do Vale do São Francisco.

A essa época, o corpo técnico da Fundação do Homem Americano soube da aprovação de funcionamento desta nova universidade no semiárido. Pela proximidade geográfica de São Raimundo Nonato com Petrolina e Juazeiro e, como já dito, em razão de pesquisas arqueológicas decisivas para a história das Ciências no Parque Nacional da Serra da Capivara, pesquisadoras da FUMDHAM e um deputado piauiense - da região de São Raimundo Nonato -, solicitaram a instalação de um campus no Piauí, que seria sede de uma graduação em Arqueologia, e tiveram êxito.

Essas questões, meramente informativas, não são menos importantes. Sabemos que arranjos políticos variados e, por vezes, controversos organizam regiões administrativas e, igualmente, universidades. Mas vale registrar que até o presente momento, nenhum dos docentes ou discentes do Colegiado de Antropologia tem desenvolvido pesquisas diretamente no Parque Nacional da Serra da Capivara, como muitas pessoas podem vir a imaginar.

A presença de um dos maiores territórios quilombolas do Brasil, o Território Quilombo Lagoas, localizado na região de São Raimundo Nonato, as manifestações religiosas (como benzimentos e reisados), a cultura popular e material, as práticas tradicionais de agricultura e pecuária, a análise de infraestruturas, de políticas e da economia local, os usos e manejo de recursos hídricos em uma região notadamente marcada pela seca e a presença (e ausência) indígena na região têm aguçado, muito mais, o olhar dos alunos e professores. Eu arrisco a dizer, que estamos em vias de consolidar uma Antropologia do Semiárido e da Caatinga.
6 Os documentos da Câmara Legislativa sobre a criação da Univasf podem ser acessados pelo seguinte endereço:https:// www.camara.leg.br/proposicoesWeb/fichadetramitacao?idProposicao=33341.Acesso em: 04 maio 2020.Parte destes debates também pode ser acessada em um dos capítulos do livro de Ricardo José Pereira Rodrigues (2019), Perfil Parlamentar 74: Osvaldo Coelho, de título "Univasf - a universidade do século XXI". 


\section{A Antropologia e o Sudeste do Piauí}

A presença (e, igualmente, ausência) de pesquisas antropológicas ou, mais precisamente, de pesquisas em Antropologia Social na região de São Raimundo Nonato e sua relação com a imponência do Parque Nacional da Serra da Capivara e mesmo com a Fundação do Homem Americano, instituição que se notabiliza pela realização de pesquisas interdisciplinares (botânica, paleontologia, zoologia, geologia, e, especialmente, arqueologia), merece um parênteses.

Na primeira vez que Niéde Guidon esteve no Sudeste do Piauí na década de 1970, numa viagem exploratória que culminou no registro fotográfico de parte das pinturas rupestres do hoje Parque Nacional da Serra da Capivara, contou com a companhia da antropóloga Vilma Chiara. Como conta a dissertação de Adriana Martins (2011), esta vinda pioneira à região foi realizada após uma missão de pesquisa entre os índios Krahô. As pesquisadoras que já estavam onde contemporaneamente se localiza o estado do Tocantins, seguiram viagem até o Piauí. Estudiosas com formação em antropologia, como Silvia Maranca e Anne-Marie Pessis, fazem parte do conselho da Fundação do Homem Americano, mas têm uma trajetória acadêmica muito mais próxima da pré-história, registro rupestre, análise de cerâmicas e, logo, da Arqueologia.

Durante o processo de demarcação da área do parque no fim da década de 1980, as antropólogas Emília Godoi e Maria Cristina Pompa fizeram parte da Missão Franco-Brasileira. O mestrado de Godoi, Trabalho da Memória: Cotidiano e História no Sertão do Piauí (1993), inclusive, foi realizado entre camponeses da comunidade Zabelê deslocados de seu território com vistas à fundação do Parque Nacional da Serra da Capivara e, ainda hoje, é a publicação em antropologia mais conhecida e citada sobre o Sudeste do Piauí. Há, portanto, um certo hiato de quase vinte anos na presença contínua de antropólogos, antropólogas e de realização de pesquisas antropológicas no Sudeste do Piauí desde a demarcação da área do parque no fim da década de 1980 (Martins, 2011), até a fundação do Colegiado de Antropologia da Univasf em 2016.

Em um artigo de título auspicioso, "Antropologia Fora dos Eixos? Algumas Considerações Sobre as Particularidades da Formação de um Campo de Pesquisas no Piauí, Brasil” (2015), Fabiano Gontijo produziu uma espécie de estado da arte da antropologia piauiense. Como o autor argumenta, ele se debruçou sobre o assunto a fim de produzir a APCN (Apresentação de Propostas de Cursos Novos) à Capes para o início das atividades no ano de 2009, do então PPGAARq (Programa de Pós-Graduação em Antropologia e Arqueologia da Universidade Federal do Piauí), desmembrado em 2013. Parte do argumento do documento é que a história da antropologia no estado é indissociável da trajetória das pesquisas da Missão Francesa ${ }^{7}$ no Sudeste do Piauí. Inclusive, a cidade de São Raimundo Nonato ganha centralidade no artigo- baseado na justificação da criação do mestrado - por sediar um escritório do IPHAN, museus, além de eventos científicos e artísticos.

Interessante notar que passados mais de dez anos do ensino de Antropologia em nível de pós-graduação no Piauí, a região de São Raimundo Nonato tenha sido
7 Para além de Niéde Guidon, outra personagem fundamental da história da antropologia piauiense narrada por Gontijo é Vilma Chiara. Ela foi professora da Universidade Federal do Piauí até o início da década de 1990, mas como mostra o artigo e mesmo o currículo, Chiara não desenvolveu pesquisas em Antropologia Social no sudeste piauiense. 
muito pouco contemplada antropológica e etnograficamente pelas pesquisas da UFPI. Conforme análise do banco de dissertações do Programa de Pós-Graduação em Antropologia da UFPI, apenas três mestrados - MATOS (2013), SILVA (2018), LIMA (2019) - contemplaram a região de São Raimundo Nonato, e todos foram realizados no mesmo lócus etnográfico: o Território Quilombo Lagoas.

Decerto a distância de Teresina de mais de $500 \mathrm{~km}$ da Serra da Capivara tenha sido um fator que dificultou estudos mais intensos na região. Mas não deixa de ser curioso que nos trabalhos mais recentes defendidos pelo PPGANT/UFPI que contemplam o Sudeste do Piauí - Do Fogo da Terra à Cozinha: Uma etnografia sobre o campesinato Quilombola, de Gerlane Dantas da Silva (2018) e Nas entranhas do sertão, nossa riqueza é o nosso chão: um estudo sobre mineração no Quilombo Lagoas (PI), de Thaís Mayara Paes de Lima (2019) - a Univasf seja descrita como um agente fundamental.

Professores e alunos da Univasf dos cursos de Arqueologia e Antropologia, via projetos de pesquisa e extensão, aparecem como personagens das pesquisas de Silva (2018) e Landim (2019). Além de mediadores de suas entradas em campo, são descritos como partícipes ativos em reuniões, rodas de conversa e audiências públicas que vêm discutindo projetos econômicos e de desenvolvimento que acontecem nas comunidades quilombolas estudadas pelas antropólogas. Não sem razão, a Univasf se faça presente nestas dissertações não apenas na lista de siglas, agradecimentos pelo apoio na realização do campo, pelos debates e estágios ou mesmo pela participação em bancas, mas a atuação de professores e alunos da universidade foi, de certo modo, etnografada por estas pesquisadoras.

Assim, os trabalhos de Landim (2019) e Silva (2019) dão pistas de que a presença do corpo discente e docente da Univasf na região - ainda que recente - já vem produzindo alguns efeitos políticos na interlocução com a cidade e com as comunidades do entorno. $\mathrm{E}$ as pesquisas produzidas pelos alunos e alunas do curso de Antropologia da Univasf nas monografias de fim de curso que estão em via de serem defendidas, tendem a produzir ainda mais efeitos, sobretudo, na produção de um conjunto necessário de saberes antropológicos, etnográficos e de políticas públicas no sudeste piauiense.

Por tudo isso, considero ter muita sorte em estar consolidando uma graduação robusta em Antropologia no Sudeste do Piauí, a primeira na Caatinga, que possui uma ampla carga teórica e temática da área da antropologia clássica e contemporânea, discussões sobre produção de relatórios, laudos e trabalhos técnicos e práticas de pesquisa e extensão (disciplinas de campo) orientadas pelo corpo docente.

Como já afirmei em outro momento, o Colegiado de Antropologia da Univasf é a mais recente graduação em Antropologia do país e o corpo docente é ainda bastante diminuto. Somos o menor colegiado de Antropologia das UF's brasileiras, com apenas 7 docentes. Mas professores e professoras atuam em diversas áreas de pesquisa: Antropologia Urbana, Antropologia Rural, Antropologia Política, Patrimônio, Antropologia da Religião, Parentesco, Antropologia da Ciência, Antropologia da Técnica, Teoria e História das Ciências Sociais, Etnologia indígena, Etnologia das populações afro-brasileiras, Relações étnico-raciais. 
Essa formação ampla do quadro docente permitiu a construção de um projeto político pedagógico bastante robusto teoricamente. Nossos alunos e alunas frequentam sete disciplinas de teoria antropológica (Introdução à Antropologia, Teoria Antropológica 1, Teoria Antropológica 2, Teoria Antropológica 3, Teoria Antropológica 4, Teoria Antropológica 5 e Teoria Antropológica 6) que dão conta de produzir um sobrevoo sobre escolas clássicas e contemporâneas de ciência antropológica. Cursam, igualmente, outra série de disciplinas obrigatórias do eixo-complementar: Antropologia Rural, Antropologia Urbana, Organização Social e Parentesco, Linguística, Etnologia Ameríndia, Etnologia Afro-Brasileira, Antropologia da Religião, Patrimônio e Museologia, Cultura Material, Teoria e História da Antropologia Brasileira, Conhecimento, Poder e Território e Antropologia e Cultura Popular. Além destas disciplinas teóricas, há um eixo metodológico composto pelos cursos de Relatórios Técnicos, Pareceres e Perícias, Métodos e Técnicas em Antropologia e dois cursos de trabalho de campo (Práticas de pesquisa e extensão). Por fim, os alunos e alunas ainda têm de frequentar seis disciplinas optativas ofertadas pelo Colegiado de Antropologia e mais duas disciplinas eletivas cursadas em outras graduações da Univasf.

Paralelamente a estas atividades de ensino, o Colegiado de Antropologia fomenta a extensão. Avalio que na Univasf, em comparação a universidades mais centrais, a extensão se faz muito mais pujante e nosso colegiado tem se destacado nisso. Conseguimos bolsas de extensão para nossos estudantes com muito mais facilidade do que conseguimos bolsas de iniciação científica, por exemplo.

Seja trabalhando com populações tradicionais da região com projetos de Cartografia Quilombola, se inserindo em programas governamentais - como os Territórios da Cidadania - ou promovendo projetos culturais e de educação - como um cineclube que promove a mostra de filmes latino-americanos que, muitas vezes, estão em cartaz nos cinemas de arte das grandes cidades e em projetos com música e cultura popular - a Antropologia da Univasf, com seus alunos e professores, tem paulatinamente alterado a dinâmica da relação dos habitantes de São Raimundo com a Universidade.

Temos ainda um esforço de interlocução com pesquisadores de outras instituições. Ao longo dos últimos três anos, realizamos seminários e palestras constantes que fazem parte de um projeto nomeado como Canteiro de Antropologia. Com o Canteiro $^{8}$, já trouxemos para o campus Serra da Capivara mais de quatro dezenas de palestrantes, entre lideranças de movimentos sociais e pesquisadores e pesquisadoras de diversas universidades brasileiras. Este é um número vigoroso, haja vista a distância de São Raimundo de aeroportos e de grandes centros de pesquisa.

Além disso, em 2019 lançamos a primeira edição de nossa revista, a Mimeo, uma publicação um tanto idiossincrática. No formato de um boletim, a Mimeo ${ }^{9}$ tem por objetivo publicar traduções de artigos de ciências humanas, críticas de textos clássicos de Literatura e Ciências Sociais, documentos diversos sobre o semiárido brasileiro e resenhas de obras com mais de 20 anos de data da publicação original, sobretudo, para subsidiar nossas disciplinas e contribuir para a formação de alunos de graduação. A proposta implícita do boletim é frear um certo apelo ao
8 Com vistas ao registro das atividades do Canteiro de Antropologia, apresento a lista de pesquisadores e lideranças de movimentos sociais que já estiveram em nosso campus até a data da submissão do presente artigo, a quem agradeço nominalmente pela contribuição na construção de debates, calorosos e diversos, no curso de Antropologia da Univasf: Guilherme Sá (UnB), Delcides Marques (Ciso - Univasf), Lux Vidal (USP), Luísa Valentini (USP), Bruno Morais (USP, PUC-PR), Erêndira Oliveira (MAE - USP),Glenn Shepard (Museu Paraense Emílio Goeldi), Emília Godoi (Unicamp), Antônio Bispo (Quilombo Saco- Cortume), Olavo de Souza Pinto (USP), Yara Alves (USP, UEMG), Gabriel Pugliesi (Ciso - Univasf), Thais Brito (UFRB), Adalton Marques (Ciso-Univasf), Daniela Caruza Ferreira (IFPI), Marina Goldfarb (UFRN), Paulo Santili (Unesp), Maria Inês Ladeira (CTI), Levi Marques Pereira (UFGD), Desirée Azevedo (UNIFESP),Tassia Rabelo de Pinho (UFPB), Maria Sueli Rodrigues de Souza (UFPI),Manoel Arraes Filho (UFPI),Átila Menezes de Lima (Geo-Univasf), Carlos Filadelfo de Aquino (UFPI), Lauriene Seraguza (USP), Marina Rocha (CPT), Jorge Mattar Villela (UFSCar), Márcia Nóbrega (Unicamp), Amarildo Malvezzi (UFPE),Claudio Teófilo Marques (Associação Quilombo Lagoas),Fernanda Peixoto (USP), Ana Claudia Marques (USP), Edmundo Peggion (Unesp), Pedro Galdino (USP), Simone Ramos (Incra), Maria Rosalina (Quilombo Tapuio), Michel Riaudel (Sorbonne Université), Celso de Brito (UFPI),Antonio Carlos de Souza Lima (MN, UFRJ), Manuela Carneiro da Cunha (USP), Mauro Almeida (Unicamp), Marcos Vinícius Guidotti (Univasf) e Sara Munhoz ( UFSCar).

9 O acesso à primeira edição da Mimeo. pode ser feito pelo seguinte endereço: http:// portais.univasf. edu.br/antropologia/mimeo 
produtivismo e à novidade de nossos tempos, queremos com a Mimeo valorizar os clássicos, aquilo que já foi publicado ou lido, pouco divulgado e, não obstante, fundamental para a formação de antropólogos e antropólogas.

Não menos importantes são as atividades de nosso "Núcleo Temático Diagnóstico Social Econômico e Cultural do Semiárido Piauiense". Nesta disciplina, que mistura pesquisa e extensão, nos propomos a produzir, com alunos e professores dos outros cursos do campus, um diagnóstico do semiárido para além de seus aspectos meramente ambientais.

O semiárido, essa região administrativa e geopolítica que abrange um conjunto de estados do nordeste brasileiro localizados num território outrora nomeado como o polígono das secas, é bem conhecido pela baixa pluviosidade, pelas especificidades da vegetação da Caatinga e, em alguma medida, pelos saberes tradicionais da população sertaneja. Mas entendemos que esta região necessita ser pensada na chave do conflito e das precariedades que igualmente a constitui. E esta é a chave analítica do "Núcleo Temático de Diagnóstico Social Econômico e Cultural do Semiárido Piauiense".

A partir de pesquisas sobre embates agrários, infraestruturas urbanas e serviços municipais, políticas de igualdade social e promoção cultural, tensões étnico-raciais e do reconhecimento de identidades, temos produzido em cada edição da disciplina relatórios técnicos capazes de subsidiar políticas públicas na região. Esses documentos, sobre os mais variados temas, escritos em conjunto por alunos e professores, vêm mostrando uma das qualidades distintivas da Antropologia: uma ciência diagnóstica, interdisciplinar e, sobretudo, com potencial técnico para subsidiar políticas e projetos de desenvolvimento comunitários.

\section{Antropologia para filhos de agricultores}

Todas as atividades que viemos realizando ao longo desses quatro anos de curso- diga-se de passagem, com pouquíssimos recursos, financiamentos ou apoio para a pesquisa - é efeito de muito trabalho de um diminuto, porém empenhado, corpo docente. É fato, no entanto, que o início de qualquer curso requer empenho e que muitos de nossos professores e professoras certamente trabalharam muito para fundar as graduações e pós-graduações em que nos formamos.

Faz-se necessário ressaltar, no entanto, que a mais nova graduação em Antropologia do país está em via de consolidação no preciso momento em que funcionários do alto escalão do Governo Federal não só fazem declarações controversas a respeito das universidades públicas brasileiras, mas atacam diretamente as ciências humanas. Impossível não se lembrar de uma declaração da máxima autoridade da educação do país em uma entrevista - de 10 de abril de 2019, logo que assumiu o cargo- que por seu tom, parecia ser dirigida aos novos cursos de Antropologia das universidades do interior do Brasil: 
são escassos. Não sou contra estudar filosofia, gosto de estudar filosofia. Mas imagina uma família de agricultores que o filho entrou na faculdade e, quatro anos depois, volta com título de antropólogo?

A maioria de nossos alunos e alunas é filha de agricultores. Como já afirmei no início deste ensaio, são jovens sertanejos do interior de São Raimundo. E a entrada desses alunos e alunas na universidade tem transformado e pode transformar ainda mais o modo como aprendemos, ensinamos, o que entendemos por antropologia e, sobretudo, os efeitos políticos e de desenvolvimento que o conhecimento antropológico pode produzir.

Como já mencionado ao longo deste artigo, na região da Serra da Capivara, há mais de 40 anos, a presença dos arqueólogos, mas igualmente de biólogos, paleontólogos e, em menor medida, de antropólogos, é uma constante. A figura do pesquisador (e no caso específico daqui de uma pesquisadora, Niéde Guidon) é, decididamente, uma posição de prestígio. Talvez daí tenha surgido a demanda popular por um curso de Antropologia, notadamente marcado pelo trabalho de pesquisa.

Mas se antes os pesquisadores e pesquisadoras vinham até São Raimundo Nonato, de outros centros universitários e com demandas externas de pesquisa, com a chegada da Univasf em 2004, passam a se construir na região outros tipos de conhecimentos instigados, na maioria das vezes, por filhos de agricultores, que ao entrarem na universidade, tornam-se pesquisadores que atualizam, a partir de novas chaves analíticas e políticas, uma série de questões.

Os sentidos do patrimônio e dos museus é, por exemplo, uma dessas questões. A região não só é sede de um patrimônio da humanidade (O Parque Nacional da Serra da Capivara), como de museus suntuosos - como o Museu do Homem Americano e o mais recente, Museu da Natureza ${ }^{10}$. Se esses equipamentos culturais projetam a Serra da Capivara para todo o país e mesmo para o mundo, igualmente, produzem efeitos nas comunidades que vivem em seu entorno.

Jovens pesquisadores das comunidades dos interiores de São Raimundo, ao entrarem em contato na universidade com as ideias de patrimônio e museus nas disciplinas dos cursos de Arqueologia e Antropologia e instigados pelos efeitos produzidos pelos equipamentos culturais imponentes da região, passam a questionar os sentidos de se patrimonializar e musealizar. Ao deslocarem a importância da pré-história (tão bem documentada no Parque Nacional da Serra da Capivara e nos demais museus) e entenderem que suas próprias comunidades têm memórias e saberes que devem ser igualmente reconhecidos e valorizados, estes estudantes ou ex-alunos agora com expertise técnica, se tornam protagonistas de políticas de musealização e patrimonialização em seus próprios interiores. Decerto a proliferação recente na região de São Raimundo Nonato de projetos de turismo e museus comunitários como os das comunidades Novo Zabelêe ${ }^{11}$,São Vitor e, mais recentemente, de Lagoa de Fora, é um dos efeitos produzidos pela presença da Univasf na região.

Esta expertise técnica em formular e consolidar políticas públicas, inclusive,
10 A Fundação do Homem Americano é responsável pela gestão de dois museus na região de São Raimundo Nonato: o Museu do Homem Americano, criado em 1994, e o recente Museu da Natureza, de 2018.Se o primeiro, localizado na sede da Fumdham, contém em seu acervo um conjunto robusto de peças arqueológicas encontradas na região, o último, muito mais suntuoso, é um museu de História Natural. No formato de uma espiral, está localizado no interior do Parque Nacional da Serra da Capivara e se destaca por sua imponência em meio à Caatinga. Completamente interativo e fazendo uso de tecnologias de realidade virtual, suas 12 salas são capazes de apresentar as mudanças paleontológicas e geológicas do planeta.

11 O caso do Museu Comunitário do Novo Zabelê é emblemático. Esta comunidade, 
tem sido reconhecida pelas comunidades do entorno que tem requerido a presença da universidade na mediação de conflitos. Os alunos, alunas e docentes do curso de Antropologia não apenas têm a oportunidade através das disciplinas de trabalho de campo e Núcleo Temático de conhecer as comunidades quilombolas do entorno, por exemplo, mas têm se tornado agentes decisivos em reuniões, audiências públicas e seminários que vêm discutindo a chegada de projetos econômicos nestas comunidades, como a mineração, tal qual elucidam as dissertações de Silva (2018) e Lima (2019).

Como me disse um estudante, a graduação em Antropologia da Univasf com suas disciplinas teóricas e de campo, bem como com a expertise técnica dos antropólogos sendo paulatinamente reconhecida na região, fez ele entender que o curso:

Trouxe margem para outra coisa. Deu acesso a um conhecimento que não tava dado pra região. A gente pode mobilizar coisas pra cidade. Porque aquilo que a gente estuda, como gênero, questões raciais, patrimônio, parentesco, juventude, fazem parte do nosso dia-a-dia.

Tal contexto, que articula vivências pessoais e familiares, experiências comunitárias bastante ativas e os conhecimentos advindos da universidade, é produtor de um tipo de alunado bastante distinto daquele dos grandes centros e que, igualmente, exige uma atualização nos modos como nós, docentes, ensinamos antropologia. Disciplinas muitas vezes temidas em outras universidades, aqui são desejadas, como por exemplo, Organização Social e Parentesco.

Se o tema pode soar abstrato em outros contextos, um não-objeto, segundo alguns autores (Schneider, [1972] 2007), aqui é vivido porque, em alguma medida, "todo mundo é parente". Com muita facilidade, durante a disciplina, alunos e alunas traçam genealogias que apresentam o seu parentesco com outros estudantes da mesma turma. Sabem que o sangue faz voto e eleição (Marques; Villela, 2017). Reconhecem que dinâmicas de reciprocidade movimentam o comércio e a política. Em São Raimundo e nos seus interiores, famílias têm reputações, trabalham juntas em suas roças e negócios. Assim, estes filhos de agricultores, quando entram na universidade, deixam de ser objetos antropológicos para se tornarem produtores de conhecimento antropológico.

Dia desses, em uma aula de Antropologia Rural, eu apresentava um trabalhoso texto do Professor Mauro Almeida, "Redescobrindo a Família Rural” (1986), que analisa minuciosamente o estatuto da família camponesa brasileira. Como professora de primeira viagem, tentava, com cautela, explicar os preceitos de Alexander Chayanov que Almeida traz em seu texto apresentando as relações entre a produção de alimentos e a unidade técnica familiar. Tentava definir o que era grupo doméstico, unidade doméstica, família nuclear, ciclo de desenvolvimento doméstico, casamento neolocal, agricultura familiar, o estatuto do camponês...

A explicação estava demasiadamente árida, até que uma das estudantes do interior de São Raimundo que apresentava o seminário do texto foi ao quadro para deslocada de seu território (Zabelê) na ocasião da fundação do Parque Nacional da Serra da Capivara, hoje vive em um assentamento rural em São Raimundo Nonato. Um ex-aluno do curso de Arqueologia da Univasf, morador no Novo Zabelê (membro de uma família de camponeses que habitava o antigo Zabelê), capitaneou a iniciativa de organizar este museu comunitário. Por meio de entrevistas com os antigos moradores e da coleta de objetos e fotografias, está organizando este equipamento cultural que narra a trajetória da comunidade e que, paulatinamente, vem sendo conhecida pela população de São Raimundo e turistas que visitam a Serra da Capivara. 
me ajudar. Desenhou a propriedade de sua família, descreveu como era a roça e o sistema de criação de cabras e gado, como consomem e onde comercializam o que produzem, como trabalham em família, onde estavam localizadas as casas e roçados, como foi herdada e distribuída aquela terra que outrora tinha sido de seus bisavós.

Todos os presentes na sala entenderam os complexos conceitos do texto de Mauro Almeida, inclusive eu. Esses conceitos, mais que compreendidos teórica ou etnograficamente, eram vividos nas trajetórias de boa parte dos alunos e alunas. Finalmente, entendi como se aprende e se ensina Antropologia e me dei conta da potência política e transformadora de uma universidade no interior do semiárido piauiense e dos conhecimentos antropológicos para filhos de agricultores.

Recebido: $18 / 05 / 2020$

Aprovado: 01/07/2020 


\section{Referências}

ALMEIDA, Mauro. Redescobrindo a família rural. Revista Brasileira de Ciências Sociais, $\mathrm{n}$. 1, p. 63-83, 1986.

BRASIL. Câmara dos Deputados. Projeto de Lei 5307/2001. Autoriza o Poder Executivo a instituir a Fundação Universidade Federal de Petrolina, e dá outras providências. Disponível em: https://www.camara.leg.br/proposicoesWeb/fichadetramitacao?Id Proposicao=33341. Acesso em: 11 nov. 2019.

COELHO, Alexandra Prado. Eduardo Viveiros de Castro: "Gostaria que o Museu Nacional permanecesse como ruína, memória das coisas mortas". Público, Lisboa, 4 set. 2018. Disponível em: https://www.publico.pt/2018/09/04/culturaipsilon/ entrevista/ eduardo-viveiros-de-castro-gostaria-que-o-museu-nacional-permanecesse-como-ruina-memoria-das-coisas-mortas-1843021. Acesso em: 10 nov. 2019.

CRUTZEN, Paul J.; STORERMER, Eugene F. The Anthropocene. IGBP [International Geosphere-Biosphere Programme]. Newsletter, n. 41, p. 17-18, 2000.

DANOWSKI, Déborah; VIVEIROS DE CASTRO, Eduardo. Há um mundo por vir? Ensaio sobre os medos e os fins. Desterro [Florianópolis]: Cultura e Barbárie, Instituto Socioambiental, 2014.

FURTADO, Celso. O Nordeste e a saga da Sudene (1958-1964). Rio de Janeiro: Contraponto, 2009.

GODOI, Emília Pietrafesa de. O trabalho da memória: um estudo antropológico de ocupação camponesa no sertão do Piauí. Dissertação (Mestrado em Antropologia Social) - Universidade Estadual de Campinas, Campinas, 1993.

GONTIJO, Fabiano de Souza. Antropologia fora dos Eixos? Algumas Considerações sobre as particularidades da formação de um campo de pesquisas no Piauí, Brasil. Revista FSA (Faculdade Santo Agostinho), n. 12, p. 49-62, 2015.

GUIDON, Niéde. Parque Nacional Serra da Capivara: modelos de preservação do patrimônio arqueológico ameaçado. Revista do Patrimônio Histórico e Artístico Nacional, n. 33, p. 75-94, 2007.

IBGE-Instituto Brasileiro de Geografia e Estatística. São Raimundo Nonato. Piauí. Disponível em: https://cidades.ibge.gov.br/brasil/pi/sao-raimundo-nonato/panorama. Acesso em: 09 nov. 2019.

LIMA, Thaís Mayara Paes. Nas estranhas do sertão, nossa riqueza é o nosso chão: um estudo sobre mineração no Território Quilombola Lagoas. Dissertação (Mestrado em Antropologia)- Universidade Federal do Piauí, Teresina, 2019.

MARTINS, Adriana Maria Ferreira. Parque Nacional da Serra da Capivara. Patrimônio Cultural da Humanidade. Dissertação (Mestrado Profissional em Bens Culturais e Projetos Sociais) -Fundação Getúlio Vargas, Rio de Janeiro, 2011.

MATOS, Simone de Oliveira. Povo de Lagoas-PI na construção da Territorialidade Quilombola: uma etnografia. Dissertação (Mestrado em Antropologia) - Universidade Federal do Piauí, Teresina, 2013.

MIMEO: Boletim de Traduções e Documentos de Antropologia e áreas afins. Colegiado de Antropologia, UNIVASF, campus São Raimundo Nonato, Piauí, n. 1, ago. 2019. Disponível em: http://portais.univasf.edu.br/antropologia/mimeo. Acesso em: 11 nov. 2019.

NÓBREGA DE OLIVEIRA, Márcia Maria. Andar mais eu: os modos de composição entre 
terras, correntezas e povoações na Ilha do Massangano, PE. Tese (Doutorado em Antropologia Social) - Universidade Estadual de Campinas, Campinas, 2019.

OLIVEIRA, Ana Stela de Negreiros. Povoamento colonial do sudeste do Piauí: indígenas e colonizadores, conflitos e resistência. Tese (Doutorado em História) -Universidade Federal de Pernambuco, Recife, 2007.

PIERSON, Donald. O Homem no Vale do São Francisco. Rio de Janeiro: SUVALE, 1972.

RODRIGUES, Ricardo José Pereira. Perfil Parlamentar 74: Osvaldo Coelho. Brasília: Câmara dos Deputados, Edições Câmara, 2019.

SCHNEIDER, David. What is kinship all about? In: PARKINAND, Robert; STONE, Lina (Eds.). Kinship and family: an anthropological reader. Maiden; Oxford; Carlton: Blackwell Publishing, 2007 [1972]. p. 257-274.

SIGAUD, Lygia. Efeitos sociais de grandes projetos hidrelétricos: as Barragens de Sobradinho e Machadinho. Comunicação do Programa de Pós-graduação em Antropologia Social do Museu Nacional, n. 9, p. 1-116, 1986.

SILVA, Gerlane Dantas da. Do fogo da terra à cozinha: uma etnografia sobre o campesinato quilombola. Dissertação (Mestrado em Antropologia) - Universidade Federal do Piauí, Teresina, 2018.

SOUTO JR., José Fernando. A engrenagem da produção de frutas: Estado, empresários e trabalhadores no Vale do São Francisco. Revista de Ciências Sociais - Política \& Trabalho, n. 50, p. 213-230, 2019.

VILLELA, Jorge Luiz Mattar; MARQUES, Ana Claudia Duarte Rocha. O sangue e a política: sobre a produção de família nas disputas eleitorais no sertão de Pernambuco. $n$. 27, p. 33-51, 2017.

VILLELA, Jorge Mattar; VIEIRA, Suzane de Alencar. Insurgências, ecologias dissidentes e antropologia modal. Goiânia: Editora da Imprensa Universitária, 2020. 